\title{
ENDOCRINE ASPECTS OF GYNAECOLOGICAL DISEASE
}

\author{
By P. M. F. Bishop, D.M., F.R.C.P.
}

Endocrinologist to Guy's Hospital, Chelsea Hospital for Women and the Department of Obstetrics and Gynaecology, Postgraduate Medical School of London

Gynaecological endocrinology is concerned with the secretion of hormones by the ovary, the control of ovarian function by the pituitary and the manifestation of ovarian activity by the behaviour of the endometrium and the character and regularity of menstrual bleeding. It is necessary, therefore, to understand the physiology of ovarian hormone secretion, its control and manifestations, the nature of the disorders induced by abnormal ovarian function, the methods of investigating them, the preparations available for treating them and the principles and results of such treatment.

\section{Physiology of the Ovary}

The ovary contains a large number of primordial follicles distributed throughout the cortex. One of these, in turn, develops into the Graafian follicle that dominates each ovarian cycle. The Graafian follicle contains an ovum embedded in granulosa cells which secrete oestrogen into the follicular fluid. At ovulation the follicle ruptures and discharges the ovum which normally enters the Fallopian tube where it may become fertilized. The theca interna surrounding the follicle proliferates until its cells have infiltrated the follicular cavity converting it into a solid structure, the corpus luteum, which continues to secrete oestrogen but also characteristically produces progesterone. The corpus luteum has an inherent life span and in due course degenerates with diminishing secretion of its hormones, and thus abdicates in favour of the developing Graafian follicle of the next ovarian cycle.

The ovarian cycle is controlled by the pituitary gonadotrophic hormones. Evidence for the existence of three gonadotrophic hormones has been obtained in certain species, such as the rat. These are the follicle-stimulating hormone (F.S.H.), the luteinizing hormone (L.H.), and the luteotrophic hormone (Lt.H.) which has been shown to be identical with prolactin. There is some doubt as to the separate existence of F.S.H. and L.H. in the human and as to whether prolactin has gonadotrophic functions. The evidence provided by experimental animals indicates that the hypo-i thalamus normally stimulates the pituitary to secrete a constant trickle of L.H. and that in its $\omega$ presence F.S.H. leads not only to enlargement: and cavitation of the Graafian follicle but also to the secretion of oestrogen into the follicular fluid.o The increasing concentration of oestrogen alters the ratio of liberation of F.S.H. and L.H. by the pituitary so that eventually the right combination is achieved that leads to ovulation. L.H. then ${ }^{\mathbb{D}}$ fades out of the picture and hands over to Lt.R. which maintains the activity of the corpus luteugio. When this wanes F.S.H. is once again released $\vec{\Phi} 0 \overrightarrow{0}$ enable the Graafian follicle of the next cycle foom develop.

The cyclical secretion of oestrogen and progesterone determines the characteristic changes in the endometrium. During the pre-ovulatoryo phase oestrogen leads to growth and proliferation, $\bar{Q}$ and after ovulation has taken place progesterone causes the endometrial glands to secrete mucusp and glycogen. The withdrawal of these two hor $-\frac{3}{2}$ mones is responsible for the shedding of the endometrium and menstrual bleeding.

Androgen is constantly secreted by the adrena? cortex and probably also by the thecal cells of the ovary. Excessive production of these adrenal and $B$. gonadal androgens may interfere with the endometrial response or possibly with the production of ovarian hormones.

Functional Disorders of the Ovary
The ovary may produce an excess of oestrogen, or of androgen, or it may undergo varying degreeso of failure. These deviations from its normaln function will give rise to certain characteristion changes in the menstrual pattern, which can $b e_{0}^{\omega}$ identified by careful history-taking and determination as to whether ovulation is taking place

\section{Excessive Oestrogen Production}

(a) Granulosa Cell Tumours.-These may occuro 
in childhood, during maturity, or after the menopause.

They are rare before puberty and indeed 95 per cent. of cases of menstrual bleeding occurring before the age of io years are due to constitutional precocious puberty. In the case of granulosa cell tumours sexual precocity is due to the oestrogen produced by the tumour and is accompanied by non-ovulatory metropathic bleeding.

During the years of maturity a granulosa cell tumour may alter the normal regular ovulatory menstrual pattern to that characteristic of metropathic bleeding, and the excessive oestrogen influence may be detected by finding an abnormally high percentage of fully cornified cells in the vaginal smear.

After the menopause uterine bleeding may recommence and adopt a metropathic pattern. One cannot, however, assume that this is caused by a granulosa-cell tumour because endometrial hyperplasia with metropathic bleeding sometimes develops spontaneously after the menopause.

(b) Metropathia Haemorrhagica.-When ovulation fails to take place the endometrium comes under the continuous influence of oestrogen unopposed by progesterone. This gradually builds up the endometrium until it becomes hyperplastic and many of the glands cystic. Eventually this thickened, polypoid endometrium is shed piecemeal so that bleeding is prolonged and may last for weeks; furthermore, it is variable in amount, sometimes consisting of profuse flooding, at other times being a mere trickle. Eventually the bleeding episode ceases and then it usually takes a considerable time before the characteristic thickened polypoid, oedematous and cystic endometrium is built up again and another bleeding episode commences. The typical pattern, therefore, is prolonged episodes of irregular bleeding alternating with protracted phases of amenorrhoea. Usually metropathia is probably simply due to the unopposed action of oestrogen on the endometrium, though the actual level of circulating oestrogen may be normal or even subnormal. Occasionally, however, excessive quantities of oestrogen are secreted, as may be demonstrated by the high cornification index of the vaginal smear.

\section{Progressively Increasing Degrees of Ovarian Deficiency}

(a) The mildest degree is delay in achieving the correct ratio of production of F.S.H. and L.H. to enable ovulation to take place so the cycle is prolonged to five or six weeks, or even two or three months (oligomenorrhoea), though ovulation eventually takes place two weeks before the onset of bleeding.

(b) Relative Failure of Progesterone Secretion.-
This commonly gives rise to menorrhagia in which the menstrual cycles are often regular, though sometimes shortened, and the bleeding is heavy. and may last for a week to ten days. Relative deficiency of progesterone is also probably the cause of the premenstrual syndrome.

(c) Regular non-ovulatory cycles. - This is probably a rare occurrence, but it is detected from time to time either by means of the basal temperature pattern or an endometrial biopsy.

(d) Non-ovulatory bleeding of the metropathic type.

(e) Amenorrhoea.-This is usually due to insufficient oestrogen being produced to stimulate the endometrium sufficiently to enable it to be shed. It may, on the other hand, be due to resistance on the part of the endometrium (the ' target organ ') to the influence of normal or even excessive amounts of circulating oestrogen.

\section{Excessive Androgen Production}

This may influence the menstrual cycle either by directly opposing ovarian activity or by inhibiting the production of gonadotrophins by the pituitary. It may lead either to oligomenorrhoea, which is not infrequently associated with cases of simple hirsutism, or to complete amenorrhoea which is the rule when the excessive androgen production results from an organic lesion of the ovary or adrenal cortex.

Adrenocortical tumours or hyperplasia giving rises to the adrenogenital syndrome are rare. So indeed are ovarian causes of excessive androgen secretion, such as virilizing tumours or the SteinLeventhal syndrome. In this condition the ovaries are enlarged, flattened, bluish-white with multiple small follicular cysts protruding through the thickened cortex. The hyperplastic theca interna probably produces a virilizing substance which is responsible for hirsutism and possibly for amenorrhoea. Failure to ovulate, however, may be due to mechanical causes, the thickened ovarian capsule preventing the follicle from rupturing.

\section{Methods of Investigating Functional Menstrual Disorders}

The first and probably the most important point to establish is whether ovulation is taking place and if so when. The easiest way of doing this is to get the patient to keep a record of her daily basal temperature. When ovulation takes place the temperature rises significantly and drops again at the onset of menstruation. The temperature pattern, however, is sometimes equivocal in which case one cannot say that ovulation has not taken place. Evidence of ovulation (or nonovulation) may then be obtained by means of 
endometrial biopsy performed preferably on the first day of bleeding. Indeed, the histological appearance of the endometrium at this time may not only provide evidence of ovulation but, in cases of menorrhagia, show that there has been inadequate progesterone influence. The estimation of urinary pregnanediol during the postovulatory phase of the cycle also indicates that the ovary is secreting progesterone, but it is still a procedure that is undertaken only by laboratories specially equipped for steroid chemistry.

Vaginal cytology is mainly employed for the detection of carcinoma of the uterus, but serial vaginal smears are of considerable value in assessing ovarian activity. By counting the number of fully cornified cells the cornification index (C.I.) can be estimated and this gives an indication of the extent of the oestrogen influence on the vaginal epithelium. Characteristic changes occur in the vaginal smear following ovulation and indicate corpus luteum activity.

Accurate methods of chemical determination of the three principal oestrogens, oestrone, oestriol and oestradiol, are now available. These determinations, however, can be carried out only in specially equipped laboratories. Single estimations are of little value, and to carry out these determinations serially throughout a menstrual cycle is a laborious, expensive and technically difficult procedure which is still a long way from becoming a routine undertaking.

The estimation of 17 -ketosteroids necessitates a 24-hour collection of urine, but is relatively simple. Its value, however, is limited. Concentrations significantly in excess of the upper limit of the female range- $15 \mathrm{mg}$. per 24 hours-are suggestive of adrenocortical over-activity, and figures below $5 \mathrm{mg}$. are found in cases of gross adrenocortical deficiency (such as Addison's disease) or pituitary failure (such as Simmonds's disease), and in myxoedema.

Urinary gonadotrophins are assayed biologically and expressed in mouse uterine weight units. If a positive result is obtained at a titre of 96 mouse units or more, conclusive evidence is provided of primary ovarian failure. Such figtures are usually found in menopausal women. Unfortunately failure to detect gonadotrophins at the 6-mouse unit titre does not necessarily indicate failure of gonadotrophin secretion.

Assessment of the functional activity of other endocrine glands may be desirable in cases of amenorrhoea, especially when the urinary gonadotrophins are low or undetectable. Thyroid function tests, such as the estimation of the B.M.R., serum cholesterol and possibly plasma concentration of ${ }^{131}$ I 48 hours after administration of a tracer dose, or the rate of urinary excretion of ${ }^{131} \mathrm{I}$ at 8,24 and 48 hours, may reveal hypothyroidism, which may be primary or secondary to pituitary deficiency. A useful screening test for adrenocortical deficiency is to determine the response to a water load. The ingestion within a quarter of an hour of up to a litre of water, following 12 hours deprivation of fluids, provides a sensitive screening test of adrenocortical function. Normally this water load induces a diuresis within two hours. Urine is collected, preferably by means of a catheter, every I 5 minutes during this two hours. If the output of urine per minute does not exceed $3 \mathrm{ml}$. then adrenocortical deficiency, either primary or secondary to pituitary failure, is likely.

\section{Endocrine Preparations Available for Clinical Use}

Oestrogens.- ' Natural' oestrogens are expensive and usually relatively weak when given by mouth. An exception is conjugated equine oestrogen which is half as potent as stilboestrol by the oral route. This preparation also has the advantage that, being water-soluble, it can be administered intravenously. The only advantage of intramuscular injection is to obtain prolonged action and it is claimed that an injection of oestradiol cyclopentylpropionate or oestradiob valerianate may promote oestrogenic activity for up to three weeks. Synthetic oestrogens are relatively cheap and potent when given by mouth Stilboestrol has the disadvantage of inducing toxic effects, such as nausea, rather frequently. Dien-oestrol is considerably less potent, though less toxic. Ethinyloestradiol is the most potent oestrogen employed therapeutically, but also has a tendency to produce nausea. Methallenoestril ( $\mathbf{R}$ 'Vallestril ') and chlorotrianisene ( $\mathbf{R}$ ' Tace ') seldom produce nausea, but are relatively expensive. The latter is said to be deposited in fat depots and therefore to have a prolonged and gradually diminishing effect, because it is "paid out' gradually into the circulation. This is claimed to be of advantage in the treatment of menopausal symptoms and also to diminish the likelihood of ' withdrawal bleeding'.

Progestogens.-Progesterone has to be given by injection to be reasonably effective at an economic price. Ethisterone (17-ethinyl testosterone) is an orally effective progestogen in doses about ten times as great as parenteral progesterone. $\mathrm{Re}$ cently a number of derivatives of 19-nortestosterone have been introduced which are as powerful as parenteral progesterone, or possibly even considerably more potent. The following have undergone fairly extensive clinical trials: ethinyl - nortestosterone, ethyl - nortestosterone, methyl-nortestosterone and ethinyl-oestraenolone. Progesterone is transient in its effect and should 
be administered daily or every other day. Esterification prolongs the effectiveness of steroids, but progesterone cannot be esterified because it contains no hydroxyl group. 17-hydroxyprogesterone caproate is said to be a potent progestogen which remains effective for about three weeks.

Androgens.-Testosterone is administered by injection in the form of its propionic ester, which remains effective for about three days. Testosterone phenylpropionate and testosterone oenanthate have a prolonged effect of up to three weeks. For oral or sublingual administration methyltestosterone is usually employed. It is claimed that other androgenic derivatives, such as methylandrostenediol and methylandrostanolone, both of which are given in the form of tablets for sublingual absorption, are primarily protein-anabolic and have comparatively little androgenic effect. They are therefore recommended as being less likely to induce undesirable side-effects such as acne and hirsutism. It is as yet not certain that these claims have been proved.

Gonadotrophins.-Two preparations are available: One is an extract of pregnant mare serum and is chiefly follicle-stimulating; the other is a preparation of chorionic gonadotrophin and is mainly luteinizing or luteotrophic. Both are effective only by intramuscular injection.

\section{The Endocrine Treatment of Menstrual Disorders}

Oligomenorrhoea. - If it is established that ovulation is taking place endocrine therapy is unlikely to improve the patient's condition. If the problem is infertility the patient should be instructed to keep basal temperature records and aim to have intercourse when the temperature rises.

Menorrhagia.-As this is usually due to a relative lack of progesterone, it would seem logical to give progesterone in the second half of the cycle. In practice this has not been very successful, though it is possible that the new 19-nortestosterone compounds possessing potent progestational activity may prove to be more effective. There seems to be some doubt, however, as to whether they induce full secretory changes in the endometrium, and these are probably essential for the complete shedding of the endometrium that leads to normal menstrual bleeding. At the present time the most effective method of dealing with this condition is to give methyltestosterone by mouth in daily doses of $10 \mathrm{mg}$. for two months. In many cases this reduces the bleeding to normal proportions. Should the menorrhagia recur after some months the course can be repeated.

The Premenstrual Syndrome.-Here again there seems to be a deficiency of progesterone and indeed progesterone by injection or ethisterone in doses of $50 \mathrm{mg}$. daily for $\mathrm{I} 4$ premenstrual days is often effective. The new i9-nortestosterone compounds are undergoing trials in these cases and have occasionally proved effective. An alternative form of treatment is the administration of methyltestosterone in daily doses of $10 \mathrm{mg}$. for two months.

Metropathia.-The established treatment of this condition is to give 'haemostatic' doses of oestrogen to stop the bleeding and progesterone in monthly courses to induce progesterone withdrawal bleeding and thereby forestall the next metropathic bleeding episode. Haemostasis is probably best achieved by injecting $20 \mathrm{mg}$. conjugated equine oestrogen intravenously and perhaps repeating the injection two or three times at intervals of 4 to 12 hours. To prevent this being followed in two or three days by an oestrogen withdrawal bleeding, the conjugated equine oestrogen is tapered off by giving conjugated equine oestrogen by mouth in daily doses of $7.5 \mathrm{mg}$. for a week, $5 \mathrm{mg}$. for a second week, and $2.5 \mathrm{mg}$. for a third week. If bleeding has not occurred during this time progesterone is injected in $25 \mathrm{mg}$. doses intramuscularly daily for four days and this should be followed in three or four days by a progesterone withdrawal bleeding which should resemble a normal period in amount and duration. Exactly a month after commencing the first course of progesterone injections another course is administered, or ethisterone $30 \mathrm{mg}$. daily by mouth for ten days is substituted for the injections. In this way a series of artificial progestogen withdrawal bleedings at monthly intervals prevents the endometrium building up into a condition of cystic glandular hyperplasia and breaking down to initiate another episode of metropathic bleeding. Limited experience of the recently introduced 19 -nortestosterone compounds has led to claims that doses of about $20 \mathrm{mg}$. daily will induce haemostasis in three or four days and that subsequent courses of daily doses of ro to $20 \mathrm{mg}$. for ten days or more will produce withdrawal bleeding from a true secretory endometrium: A few authors claim that chorionic gonadotrophin may in some cases induce ovulation and if repeated a number of times eventually give rise to spontaneous ovulatory cycles. In approximately half of a small series of women in which the metropathia was neither pubertal, puerperal nor premenopausal, ovulatory cycles continued for at least a year after cessation of the treatment, which consisted of giving 600 I.U. of chorionic gonadotrophin daily for five injections, then a month later for four injections, then three injections and so on.

Amenorrhoea.-Experience of endocrine therapy in amenorrhoea has, in most clinics, been dis- 
appointing. It is nearly always possible to induce oestrogen withdrawal bleedings or, if the endometrium is sufficiently primed with endogenous oestrogen, progesterone withdrawal bleedings. In the majority of cases, however, such withdrawal bleedings do not lead subsequently to spontaneous ovulatory cycles. Most clinics have been equally disappointed with the results of gonadotrophin therapy. A few, however, claim spectacular success. In one clinic, for instance, administration of 1,500 to 3,000 I.U. of serum gonadotrophin given daily for five injections $\$$ followed by 1,500 I.U. chorionic gonadotrophin on alternate days for three injections, has led sometimes after repeated courses at monthlys intervals, to spontaneous ovulatory cycles, and iro some cases to pregnancy, in about $5 \circ$ per cent. ofo women with low urinary gonadotrophin outputen and amenorrhoea of not more than two years duration.

\section{CARDIAC DISEASE}

Price 3s. 11d. post free

INTRODUCTION

Walter Somerville, M.D., M.R.C.P.

ANGIOGRAPHY

J. Norman Pattinson, M.B., B.Chir., D.M.R.D., F.F.R.

BEDSIDE DIAGNOSIS OF CONGENITAL HEART DISEASE

Walter Somerville, M.D., M.R.C.P.

SURGICAL TREATMENT OF CONGENITAL HEART DISEASE

W. P. Cleland, M.R.C.P., F.R.C.S.

PREGNANCY AND RHEUMATIC HEART DISEASE

Samuel Oram, M.D., F.R.C.P.
DRUG TREATMENT OF HYPERTENSION

E. G. McQueen, M.B., M.R.C.P., and F.H.

Smirk, M.D., F.R.C.P.

TREATMENT OF BACTERIAL

ENDOCARDITIS

Ian G. W.Hill, C.B.E., T.D., M.B., F.R.C.P.E., M.R.C.P., F.R.S.E.

THE MANAGEMENT OF COR PULMONALE J. F. Goodwin, M.D., M.R.C.P.

THE CARDIAC RISK IN ANAESTHESIA AND SURGERY

Graham W. Hayward, M.D., F.R.C.P.

Published by

THE FELLOWSHIP OF POSTGRADUATE MEDICINE

60, Portland Place, London, W.1

\section{RUTHIN CASTLE, NORTH WALES}

A Clinic for the diagnosis and treatment of Internal Diseases (except Mental or Infectious Diseases). The Clinic is provided with a staff of doctors, technicians and nurses.

The surroundings are beautiful. The climate is mild. There is central heating throughout. The annual rainfall is $\mathbf{3 0 . 5}$ inches, that is less than the average for England.

The Fees are inclusive and vary according to the room occupied.

For particulars apply to THE SECRETARY, Ruthin Castle, North Wales. 